\title{
The role of leptin in diabetes: metabolic effects
}

\author{
Thomas H. Meek ${ }^{1}$ Gregory J. Morton ${ }^{1}$
}

Received: 13 November 2015 / Accepted: 22 January 2016/Published online: 11 March 2016

(C) Springer-Verlag Berlin Heidelberg 2016

\begin{abstract}
While it is well established that the adiposity hormone leptin plays a key role in the regulation of energy homeostasis, growing evidence suggests that leptin is also critical for glycaemic control. In this review we examine the role of the brain in the glucose-lowering actions of leptin and the potential mediators responsible for driving hyperglycaemia in states of uncontrolled insulin-deficient diabetes (uDM). These considerations highlight the possibility of targeting leptin-sensitive pathways as a therapeutic option for the treatment of diabetes. This review summarises a presentation given at the 'Is leptin coming back?' symposium at the 2015 annual meeting of the EASD. It is accompanied by two other reviews on topics from this symposium (by Christoffer Clemmensen and colleagues, DOI: 10.1007/s00125-016-3906-7, and by Gerald Shulman and colleagues, DOI: 10.1007/s00125-016-3909-4) and an overview by the Session Chair, Ulf Smith (DOI: 10.1007/ s00125-016-3894-7).
\end{abstract}

Keywords Brain · Corticosterone · Diabetes · Glucagon · Hepatic glucose production $\cdot$ Leptin $\cdot$ Review
Abbreviations
CNS
Central nervous system
CRR
Counter-regulatory response

Gregory J. Morton

gjmorton@u.washington.edu

1 Diabetes and Obesity Center of Excellence, Department of Medicine, University of Washington at South Lake Union, 850 Republican St., N335, Box 358055, Seattle, WA 98195, USA
HGP Hepatic glucose production

i.c.V Intracerebroventricular

POMC Pro-opiomelanocortin

STZ Streptozotocin

STZ-DM Streptozotocin-induced diabetes mellitus

uDM Uncontrolled insulin-deficient diabetes

VMN Ventromedial nucleus

\section{Introduction}

Diabetes is increasing steadily all over the world. The International Diabetes Federation estimates that more than 382 million people have diabetes globally and this number is expected to exceed 590 million by 2035 [1]. This is a serious health concern since people with diabetes are vulnerable to both short- and long-term complications, including cardiovascular and renal disease, blindness and amputation [2]. Given the continued prevalence and incidence of diabetes and its considerable health burden, a better understanding of its pathogenesis is required to facilitate the development of new strategies for its treatment.

Ever since its discovery [3], insulin has been the mainstay for the treatment of uncontrolled insulin-deficient diabetes mellitus ( $\mathrm{uDM}$ ). In fact, because of severe beta cell deficiency, the administration of exogenous insulin is necessary for survival. However, despite progress in understanding the causes, consequences and progression of diabetes, and the advancements in the development of insulin and its analogues, maintaining tight glycaemic control without adverse consequences such as hypoglycaemia and weight gain still remains a challenge [4-6]. This further highlights the need for alternative approaches or adjuncts to insulin. 


\section{Leptin regulation of glucose metabolism}

Growing evidence suggests that, in addition to the regulation of energy homeostasis, the adiposity hormone leptin also plays a key role in glucose metabolism [7]. In support of this, rodent models of leptin deficiency are characterised by insulin resistance and diabetes $[8,9]$, and leptin treatment lowers blood glucose and insulin levels [10] independent of changes in food intake and body weight [11]. Moreover, leptin administration in both rodents [12, 13] and humans [14] ameliorates the severe insulin resistance and diabetes phenotype characteristic of other models of leptin deficiency that are not associated with obesity, such as lipodystrophy, a condition characterised by loss of adipose tissue owing to mutations that impair adipogenesis [15]. Taken together, these data suggest that leptin regulates glycaemic control in addition to energy balance in both rodent models and clinical settings.

Recent evidence suggests that leptin also has glucoselowering effects in uDM [16, 17], another model of acquired leptin deficiency [18]. Because insulin is required for the synthesis and storage of triacylglycerol into adipose tissue, in the absence of insulin therapy in uDM there is a depletion of body fat stores. This rapid, progressive loss of body fat stores is accompanied by a pronounced decrease in plasma leptin levels [18]. Thus, uDM is characterised by hyperglycaemia and hyperphagia, and both insulin- and leptin-deficiency have been implicated in these responses.

Since the central nervous system (CNS) plays a critical role in mediating the majority of the actions of leptin on energy homeostasis, we and others hypothesised that the glucoselowering effects of leptin are mediated by the brain. In support of this, leptin administration directly into the brain, at doses that have no effect when administered peripherally, normalises blood glucose levels in rodent models of uDM [19-22]. This glucose-lowering effect of leptin occurs via a mechanism that is independent of reduced food intake, increased urinary glucose loss or recovery of pancreatic beta cells. Moreover, this glucose-lowering effect of leptin occurs via an insulinindependent mechanism characterised by a normalisation of hepatic glucose production (HGP) and increased rates of glucose uptake in peripheral tissues, including brown adipose tissue, muscle and heart [20]. Collectively, these data establish that leptin signalling in the brain in uDM has the capacity to normalise diabetic hyperglycaemia.

\section{Mechanisms mediating the glucose-lowering effects of leptin}

The mechanism(s) that mediates the glucose-lowering effects of leptin in $\mathrm{uDM}$ remains to be fully elucidated and is an area of active investigation. $\mathrm{uDM}$ is characterised by hyperphagia, hyperglucagonaemia and hypercorticosteronaemia, and each of these is thought to increase glucose production and promote hyperglycaemia [23]. At the same time, the hypothalamicpituitary-thyroid (HPT) axis is inhibited and, similar to other conditions of leptin deficiency ( $o b / o b$ mice and fasting), each of these abnormalities is corrected by leptin treatment [24].

Several lines of evidence implicate hyperglucagonaemia in the hyperglycaemia and ketosis characteristic of uDM [25], and indicate that the glucose-lowering action of leptin is mediated via a normalisation of plasma glucagon levels. For example, hyperglucagonaemia is a hallmark of diabetes in both humans and rodent models [26, 27], and the suppression of glucagon by somatostatin in a pharmacologically induced dog model of diabetes or in humans with type 1 diabetes lowers blood glucose and HGP $[28,29]$. Recent findings suggest that hyperglucagonaemia is required for diabetic hyperglycaemia, since glucagon receptor null ( $\left.\mathrm{Ccgr}^{-/}\right)$-mice fail to develop streptozotocin (STZ; a beta cell toxin)-induced diabetes mellitus (STZ-DM) [30], an effect reversed by restoration of glucagon receptor signalling to the liver [31]. Furthermore, evidence suggests that the glucose-lowering effects of leptin in $\mathrm{UDM}$ are accompanied by a normalisation of plasma glucagon levels $[17,19,20]$.

However, a similar argument has been made regarding the role of the hypothalamic-pituitary-adrenal (HPA) axis, as $\mathrm{uDM}$ is characterised by increased glucocorticoid secretion [32] and this response is also reversed by intracerebroventricular (i.c.v.) infusion of leptin [20]. Recent work further indicates that when fasted rats are studied within $24 \mathrm{~h}$ after induction of STZ-DM, the normalisation of elevated corticosterone levels by leptin is sufficient to account for the normalisation of hyperglycaemia, while plasma glucagon levels remain elevated [33]. Thus, reversal of hyperglucagonaemia and HPA axis activation have each been separately advanced to explain the glucose-lowering effects of leptin [17,33], yet data suggest that once $\mathrm{uDM}$ is established, neither mechanism is sufficient to explain leptin's glucose-lowering actions.

For example, the hypothesis that leptin-mediated reversal of HPA axis activation explains its glucose-lowering effects [33] predicts that circulating corticosterone levels must be elevated for diabetic hyperglycaemia to occur, but previous studies demonstrate that adrenalectomy (ADX) does not prevent hyperglycaemia from developing in rats with $\mathrm{uDM}$ fed ad libitum $[32,34,35]$, and that the ability of leptin to lower plasma glucocorticoid levels is not required for its glucoselowering actions $[34,36]$. Thus, normalisation of corticosterone levels cannot by itself fully explain leptin's glucoselowering effects $[33,34]$. While the discrepancy between these findings is not readily apparent, differences in the severity and duration of $\mathrm{uDM}$, or other environmental factors may play a role.

Similarly, the observation that $\mathrm{Gcgr}^{-/}$mice are protected from hyperglycaemia following STZ is confounded by the 
marked increase in circulating levels of both glucagon like peptide-1 (GLP-1) and fibroblast growth factor-21 [37, 38], which appear to protect against diabetes irrespective of deficient glucagon signalling. In addition, neither systemic administration of the GLP-1 receptor agonist liraglutide, which reverses hyperglucagonaemia in STZ-DM rats, nor administration of a glucagon-neutralising antibody, when used at a dose that ameliorates diabetic ketosis (and blocks glucagoninduced hyperglycaemia in non-diabetic rats), has any impact on either diabetic hyperglycaemia [39] or elevated rates of HGP. Moreover, physiological leptin replacement in STZDM rats is sufficient to normalise both plasma glucagon and corticosterone levels [36], but has little effect on diabetic hyperglycaemia, suggesting that the normalisation of these two hormones is insufficient to explain the potent glucoselowering effect of i.c.v. leptin.

We therefore propose that in the setting of established uDM, hyperphagia, hyperglucagonaemia and hypercorticosteronaemia, are among several redundant mechanisms that contribute to diabetic hyperglycaemia (Fig. 1). Thus, in order to reverse diabetic hyperglycaemia, leptin must simultaneously normalise several neuroendocrine and autonomic responses, and reversal of one alone is insufficient. This is analogous to the counter-regulatory

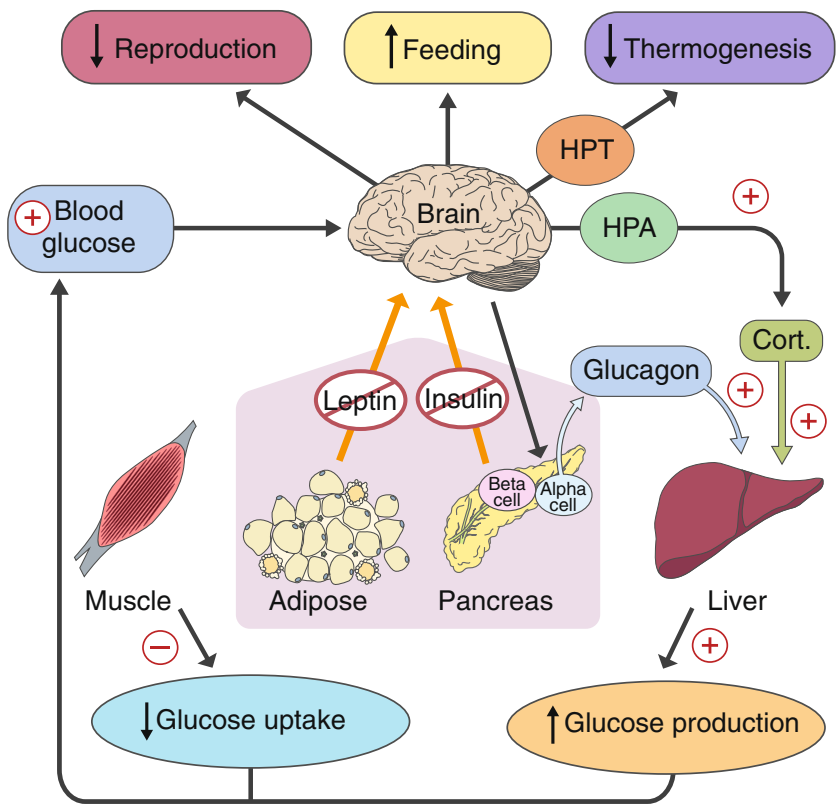

Fig. 1 Normalisation of blood glucose levels by leptin in uDM. uDM is characterised by hyperglycaemia and both insulin- and leptin-deficiency because of the loss of pancreatic beta cells and subsequent depletion of adipose tissue stores, respectively. In response to reduced insulin and leptin signalling, the brain initiates a set of behavioural, autonomic and neuroendocrine responses designed to raise blood glucose levels. This effect is mediated by both a reduction in peripheral tissue glucose uptake and increased rates of HGP, attributable in part, to increased glucagon secretion from pancreatic alpha cells and activation of the HPA axis. CNS leptin administration normalises hyperglycaemia in $\mathrm{UDM}$ by both potently suppressing HGP and increasing glucose uptake despite persistent severe insulin deficiency, an effect associated with the normalisation of both elevated plasma glucagon and corticosterone (Cort.) levels response (CRR) to hypoglycaemia, an 'emergency state' in which the brain perceives a fall in energy availability (i.e. blood glucose). In response to hypoglycaemia, several redundant mechanisms are engaged to raise blood glucose levels, including stimulation of food intake, activation of the HPA axis, stimulation of glucagon secretion and inhibition of insulin secretion [40]. Interestingly, many of the same metabolic and neuroendocrine responses engaged during hypoglycaemia are also elicited during conditions characterised by leptin deficiency, including $\mathrm{uDM}$. However, given the redundant nature of the CRR system, the ability to recover from hypoglycaemia remains largely intact when a single component of the response is blocked [40] but is dramatically impaired if two or more (e.g. both adrenal and glucagon) responses are blocked [28, 41, 42]. Thus, although both adrenal and glucagon responses contribute, neither is required because of the extensive redundancy built into the CRR.

\section{Neurocircuitry controlling leptin's glucose-lowering effects}

While leptin receptors are expressed throughout the brain, including several hypothalamic and extrahypothalamic areas involved in the control of energy balance and autonomic function [43], several observations implicate a role for the hypothalamic ventromedial nucleus (VMN) in the glucose-lowering effects of leptin in $\mathrm{uDM}$. In support of this, neurons in the VMN express the leptin receptor [43] and are activated by leptin [44], injection of leptin into this brain area increases glucose uptake in peripheral tissues $[45,46]$ and deletion of leptin receptors from neurons in the VMN causes mild obesity and an insulinresistant phenotype in mice $[47,48]$. In addition, this brain area is also involved in the control of glucagon secretion [49].

Based on these observations, we hypothesised a role for the VMN in mediating the glucose-lowering actions of leptin. Our findings demonstrated that leptin administration to the VMN (at a tenfold lower dose than given i.c.v.) was sufficient to normalise blood glucose levels and other metabolic disturbances associated with $\mathrm{uDM}$ [50]. This glucose-lowering effect was also accompanied by the normalisation of both increased HGP and hyperglucagonaemia characteristic of uDM [50]. However, in mice in which leptin receptors were deleted from VMN neurons, the glucose-lowering effects of CNS leptin remained intact [50]. Thus, leptin signalling in the VMN is sufficient, but not required to lower blood glucose levels in $\mathrm{uDM}$ and suggests that the VMN may be part of a distributed network through which leptin can act to lower glucose independently of insulin.

Additional studies have further examined the CNS mechanism(s) whereby leptin normalises blood glucose levels in $\mathrm{uDM}$. The available evidence suggests that the glucoselowering effects of leptin require melanocortin signalling [51, 52]; however, increased CNS melanocortin signalling is not sufficient to lower blood glucose levels in $\mathrm{uDM}$ [51, 52]. Consistent 
with this, i.c.v. leptin administration failed to normalise blood glucose levels in leptin receptor-deficient mice in which leptin receptors were re-expressed in pro-opiomelanocortin (POMC) neurons [53]. By contrast, re-expression of leptin signalling to both $\gamma$-aminobutyric acid (GABA) and POMC neurons in otherwise leptin receptor-deficient mice is sufficient to mediate the majority of the glucose-lowering effects of leptin [53]. Future studies are further warranted to better characterise and understand the neurons and neurocircuits that mediate the glucose-lowering and other neuroendocrine effects of leptin in $\mathrm{uDM}$. To facilitate this, new advancements in neuroscience technologies, such as optogenetics and designer receptors exclusively activated by designer drugs (DREADDs), hold promise in the functional mapping and manipulation of discrete populations of cells involved in glycaemic control $[54,55]$, similar to that which has been applied to increase our knowledge of feeding behaviour [56-58].

\section{Conclusions}

The research following the discovery of the hormone leptin more than two decades ago [59] has fundamentally increased our understanding of the CNS mechanisms regulating energy homeostasis. However, while the therapeutic potential of leptin for the treatment of obesity remains limited [60], as leptin plays a key role in glycaemic control, independent of its effects on energy balance, it might be useful as a therapy for other conditions. Leptin therapy has already been approved for the treatment of lipodystrophy and has glucose-lowering effects in rodent models of type 1 and type 2 diabetes [61]. This raises the possibility that leptin may be a potentially useful adjunct to insulin treatment in the management of diabetes.

Funding Work in the authors' laboratories is supported by National Institutes of Health grants DK089056 (to GJM), an NIH K01 Career Development Award DK097859 (to THM), and by the Nutrition Obesity Research Center (NORC, DK035816), the Diabetes Research Center (DRC, DK17047) at the University of Washington.

Duality of interest The authors declare that there is no duality of interest associated with this manuscript.

Contribution statement GJM and THM were both responsible for drafting the article, revising it critically for important intellectual content and approved the version to be published.

\section{References}

1. International Diabetes Federation (2013) IDF diabetes atlas, 6th edn. International Diabetes Federation, Brussels
2. Chen L, Magliano DJ, Zimmet PZ (2011) The worldwide epidemiology of type 2 diabetes mellitus - present and future perspectives. Nat Rev Endocrinol 8:228-236

3. Banting FG, Best CH (1990) Pancreatic extracts. 1922. J Lab Clin Med 115:254-272

4. The DCCT Research Group (1988) Weight gain associated with intensive therapy in the diabetes control and complications trial. Diabetes Care 11:567-573

5. The Diabetes Control and Complications Trial Research Group (1993) The effect of intensive treatment of diabetes on the development and progression of long-term complications in insulindependent diabetes mellitus. N Engl J Med 329:977-986

6. The Diabetes Control and Complications Trial Research Group (1997) Hypoglycemia in the diabetes control and complications trial. Diabetes 46:271-286

7. Morton GJ, Schwartz MW (2011) Leptin and the central nervous system control of glucose metabolism. Physiol Rev 91:389-411

8. Dubuc PU (1976) The development of obesity, hyperinsulinemia, and hyperglycemia in $o b / o b$ mice. Metabolism 25:1567-1574

9. Wyse BM, Dulin WE (1970) The influence of age and dietary conditions on diabetes in the $d b$ mouse. Diabetologia 6:268-273

10. Pelleymounter MA, Cullen MJ, Baker MB et al (1995) Effects of the obese gene product on body weight regulation in $o b / o b$ mice. Science 269:540-543

11. Schwartz MW, Baskin DG, Bukowski TR et al (1996) Specificity of leptin action on elevated blood glucose levels and hypothalmic neuropeptide Y gene expression in $o b / o b$ mice. Diabetes 45:531535

12. Gavrilova O, Marcus-Samuels B, Leon LR, Vinson C, Reitman ML (2000) Leptin and diabetes in lipoatrophic mice. Nature 403:850, discussion $850-851$

13. Shimomura I, Hammer RE, Ikemoto S, Brown MS, Goldstein JL (1999) Leptin reverses insulin resistance and diabetes mellitus in mice with congenital lipodystrophy. Nature 401:73-76

14. Petersen KF, Oral EA, Dufour S et al (2002) Leptin reverses insulin resistance and hepatic steatosis in patients with severe lipodystrophy. J Clin Invest 109:1345-1350

15. Patni N, Garg A (2015) Congenital generalized lipodystrophiesnew insights into metabolic dysfunction. Nat Rev Endocrinol 11: $522-534$

16. Chinookoswong N, Wang JL, Shi ZQ (1999) Leptin restores euglycemia and normalizes glucose turnover in insulin-deficient diabetes in the rat. Diabetes 48:1487-1492

17. Yu X, Park BH, Wang MY, Wang ZV, Unger RH (2008) Making insulin-deficient type 1 diabetic rodents thrive without insulin. Proc Natl Acad Sci U S A 105:14070-14075

18. Havel PJ, Uriu-Hare JY, Liu T et al (1998) Marked and rapid decreases of circulating leptin in streptozotocin diabetic rats: reversal by insulin. Am J Physiol 274:R1482-R1491

19. Fujikawa T, Chuang JC, Sakata I, Ramadori G, Coppari R (2010) Leptin therapy improves insulin-deficient type 1 diabetes by CNSdependent mechanisms in mice. Proc Natl Acad Sci U S A 107: 17391-17396

20. German JP, Thaler JP, Wisse BE et al (2011) Leptin activates a novel CNS mechanism for insulin-independent normalization of severe diabetic hyperglycemia. Endocrinology 152:394-404

21. Hidaka S, Yoshimatsu H, Kondou S et al (2002) Chronic central leptin infusion restores hyperglycemia independent of food intake and insulin level in streptozotocin-induced diabetic rats. FASEB J 16:509-518

22. Lin CY, Higginbotham DA, Judd RL, White BD (2002) Central leptin increases insulin sensitivity in streptozotocin-induced diabetic rats. Am J Physiol Endocrinol Metab 282:E1084-E1091

23. Morton GJ, Meek TH, Schwartz MW (2014) Neurobiology of food intake in health and disease. Nat Rev Neurosci 15:367-378 
24. Ahima RS, Prabakaran D, Mantxoros C et al (1996) Role of leptin in the neuroendocrine response to fasting. Nature 382:250-252

25. Unger RH, Cherrington AD (2012) Glucagonocentric restructuring of diabetes: a pathophysiologic and therapeutic makeover. J Clin Invest 122:4-12

26. Dobbs R, Sakurai H, Sasaki H et al (1975) Glucagon: role in the hyperglycemia of diabetes mellitus. Science 187:544-547

27. Muller WA, Faloona GR, Unger RH (1971) The effect of experimental insulin deficiency on glucagon secretion. J Clin Invest 50: 1992-1999

28. Gerich J, Davis J, Lorenzi M et al (1979) Hormonal mechanisms of recovery from insulin-induced hypoglycemia in man. Am J Physiol 236:E380-E385

29. Raskin P, Unger RH (1978) Hyperglucagonemia and its suppression. N Engl J Med 299:433-436

30. Lee Y, Wang MY, Du XQ, Charron MJ, Unger RH (2011) Glucagon receptor knockout prevents insulin-deficient type 1 diabetes in mice. Diabetes 60:391-397

31. Lee Y, Berglund ED, Wang MY et al (2012) Metabolic manifestations of insulin deficiency do not occur without glucagon action. Proc Natl Acad Sci U S A 109:14972-14976

32. Strack AM, Sebastian RJ, Schwartz MW, Dallman MF (1995) Glucocorticoids and insulin: reciprocal signals for energy balance. Am J Physiol 268:R142-R149

33. Perry RJ, Zhang XM, Zhang D et al (2014) Leptin reverses diabetes by suppression of the hypothalamic-pituitary-adrenal axis. Nat Med 20:759-763

34. Morton GJ, Meek TH, Matsen ME, Schwartz MW (2015) Evidence against hypothalamic-pituitary-adrenal axis suppression in the anti-diabetic action of leptin. J Clin Invest 125:4587-4591

35. Schwartz MW, Strack AM, Dallman MF (1997) Evidence that elevated plasma corticosterone levels are the cause of reduced hypothalamic corticotrophin-releasing hormone gene expression in diabetes. Regul Pept 72:105-112

36. German JP, Wisse BE, Thaler JP et al (2010) Leptin deficiency causes insulin resistance induced by uncontrolled diabetes. Diabetes 59:1626-1634

37. Omar BA, Andersen B, Hald J, Raun K, Nishimura E, Ahren B (2014) Fibroblast growth factor 21 (FGF21) and glucagon-like peptide 1 contribute to diabetes resistance in glucagon receptordeficient mice. Diabetes 63:101-110

38. Gelling RW, Du XQ, Dichmann DS et al (2003) Lower blood glucose, hyperglucagonemia, and pancreatic alpha cell hyperplasia in glucagon receptor knockout mice. Proc Natl Acad Sci U S A 100: 1438-1443

39. Meek TH, Dorfman MD, Matsen ME et al (2015) Evidence that in uncontrolled diabetes, hyperglucagonemia is required for ketosis but not for increased hepatic glucose production or hyperglycemia. Diabetes 64:2376-2387

40. Cryer PE (2004) Diabetes mellitus: a fundamental and clinical text. Lippincott Williams \& Wilkins, Philadelphia

41. Rizza RA, Cryer PE, Gerich JE (1979) Role of glucagon, catecholamines, and growth hormone in human glucose counterregulation. Effects of somatostatin and combined alpha- and beta-adrenergic blockade on plasma glucose recovery and glucose flux rates after insulin-induced hypoglycemia. J Clin Investig 64:62-71

42. Rosen SG, Clutter WE, Berk MA, Shah SD, Cryer PE (1984) Epinephrine supports the postabsorptive plasma glucose concentration and prevents hypoglycemia when glucagon secretion is deficient in man. J Clin Invest 73:405-411

43. Elmquist JK, Bjorbaek C, Ahima RS, Flier JS, Saper CB (1998) Distributions of leptin receptor mRNA isoforms in the rat brain. J Comp Neurol 395:535-547
44. Munzberg H, Flier JS, Bjorbaek C (2004) Region-specific leptin resistance within the hypothalamus of diet-induced obese mice. Endocrinology 145:4880-4889

45. Haque MS, Minokoshi Y, Hamai M, Iwai M, Horiuchi M, Shimazu $\mathrm{T}$ (1999) Role of the sympathetic nervous system and insulin in enhancing glucose uptake in peripheral tissues after intrahypothalamic injection of leptin in rats. Diabetes 48:17061712

46. Minokoshi Y, Haque MS, Shimazu T (1999) Microinjection of leptin into the ventromedial hypothalamus increases glucose uptake in peripheral tissues in rats. Diabetes 48:287-291

47. Bingham NC, Anderson KK, Reuter AL, Stallings NR, Parker KL (2008) Selective loss of leptin receptors in the ventromedial hypothalamic nucleus results in increased adiposity and a metabolic syndrome. Endocrinology 149:2138-2148

48. Dhillon H, Zigman JM, Ye C et al (2006) Leptin directly activates SF1 neurons in the VMH, and this action by leptin is required for normal body-weight homeostasis. Neuron 49:191-203

49. Nonogaki K, Iguchi A (1997) Role of central neural mechanisms in the regulation of hepatic glucose metabolism. Life Sci 60:797-807

50. Meek TH, Matsen ME, Dorfman MD et al (2013) Leptin action in the ventromedial hypothalamic nucleus is sufficient, but not necessary, to normalize diabetic hyperglycemia. Endocrinology 154: 3067-3076

51. da Silva AA, do Carmo JM, Freeman JN, Tallam LS, Hall JE (2009) A functional melanocortin system may be required for chronic CNS-mediated antidiabetic and cardiovascular actions of leptin. Diabetes 58:1749-1756

52. Meek TH, Matsen ME, Damian V, Cubelo A, Chua SC Jr, Morton GJ (2014) Role of melanocortin signaling in neuroendocrine and metabolic actions of leptin in male rats with uncontrolled diabetes. Endocrinology 155:4157-4167

53. Fujikawa T, Berglund ED, Patel VR et al (2013) Leptin engages a hypothalamic neurocircuitry to permit survival in the absence of insulin. Cell Metab 18:431-444

54. Flak JN, Patterson CM, Garfield AS et al (2014) Leptin-inhibited PBN neurons enhance responses to hypoglycemia in negative energy balance. Nat Neurosci 17:1744-1750

55. Garfield AS, Shah BP, Madara JC et al (2014) A parabrachialhypothalamic cholecystokinin neurocircuit controls counterregulatory responses to hypoglycemia. Cell Metab 20: $1030-1037$

56. Carter ME, Soden ME, Zweifel LS, Palmiter RD (2013) Genetic identification of a neural circuit that suppresses appetite. Nature 503:111-114

57. Aponte Y, Atasoy D, Sternson SM (2011) AGRP neurons are sufficient to orchestrate feeding behavior rapidly and without training. Nat Neurosci 14:351-355

58. Krashes MJ, Koda S, Ye C et al (2011) Rapid, reversible activation of AgRP neurons drives feeding behavior in mice. J Clin Invest 121:1424-1428

59. Zhang Y, Proenca R, Maffei M, Barone M, Leopold L, Friedman JM (1994) Positional cloning of the mouse obese gene and its human homologue. Nature 372:425-432

60. Farr OM, Gavrieli A, Mantzoros CS (2015) Leptin applications in 2015: what have we learned about leptin and obesity? Curr Opin Endocrinol Diabetes Obes 22:353-359

61. Cummings BP, Bettaieb A, Graham JL et al (2011) Subcutaneous administration of leptin normalizes fasting plasma glucose in obese type 2 diabetic UCD-T2DM rats. Proc Natl Acad Sci U S A 108: $14670-14675$ 